\title{
Ouvindo outras vozes: relato de familiares sobre o convívio com o paciente psiquiátrico*
}

HEARING OTHER VOICES: THE STORY OF RELATIVES ABOUT THE LIVING WITHTHE PSYCHIATRIC PATIENT

\author{
ESCUCHANDO OTRAS VOCES: RELATOS DE FAMILIARES SOBRE \\ LA CONVIVENCIA CON EL PACIENTE PSIQUIÁTRICO
}

\section{Amanda Márcia dos Santos Reinaldoํㅜ, Toyoko Saeki²}

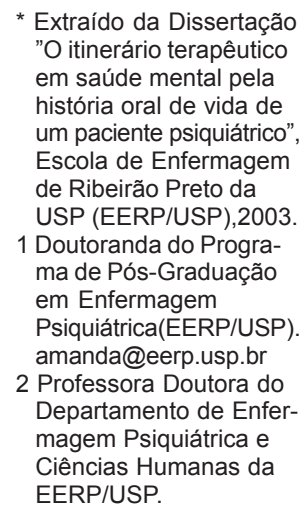

\begin{abstract}
RESUMO
Neste artigo apresentamos alguns resultados de um estudo que abordou o itinerário terapêutico de um paciente psiquiátrico pela história oral de vida, sob o prisma da antropologia, no qual priorizamos as narrativas dos sujeitos para apreender a experiência do vivido. Adotamos uma metodologia qualitativa, de caráter descritivo, centrada na análise das narrativas da pessoa em sofrimento psíquico e complementada pelas narrativas de seus familiares. A coleta de dados constou de entrevistas e observação participante. Temas, como solidão, rotina, dificuldade de conviver com a doença, permearam esses momentos e nortearam a discussão dos resultados.
\end{abstract}

\section{DESCRITORES}

Família.

Pessoas mentalmente doentes. Narração.

\section{ABSTRACT}

We present on this article some findings from a study on the therapeutic itinerary of a psychiatric patient through his verbal history of life using the anthropological approach, in which we had as priority the narratives of the subjects to obtain the individual's living experience. It was adopted a descriptive, qualitative methodology centered on the analysis of the narratives from the person in psychic suffering and it was complemented by his relatives. Data collection consisted of interviews and participative observation. Themes as loneliness, routine and difficulty of living with the disease encircled these moments and guided the discussion of the results.

\section{DESCRIPTORS}

Family.

Mentally ill persons.

Narration.

\section{RESUMEN}

Se presentam algunos resultados de un estudio que abordó el itinerario terapéutico de un paciente psiquiátrico por la historia oral de vida, desde la óptica de la antropología, donde priorizamos las narrativas de los sujetos para apreender la experiencia de lo vivido. Fue aplicada la metodología cualitativa de carácter descriptivo, centrado en el analise de las narraciones de la persona en sufrimiento psíquico y complementada por las narraciones de sus familiares. La recolección de datos fue por entrevistas y observación participante. Temas como soledad, rutina y dificultad de convivir con la enfermedad rodea esos momentos y demarcaran la discusión de los resultados.

\section{DESCRIPTORES}

Familia.

Persona mentalmente enferma. Narración. 


\section{INTRODUÇÃO}

As relações que se desenvolvem entre as situações de doença e cura mostram-se especialmente relevantes nos estudos das diferentes abordagens terapêuticas adotadas pelos doentes ${ }^{(1)}$. Os familiares de alguns pacientes com doença mental oferecem, em suas narrativas, exemplos da complexidade de itinerários terapêuticos e a dificuldade de explicá-los no que concerne a certas escolhas de tratamentos.

O itinerário terapêutico é uma cadeia de eventos sucessivos que formam uma trajetória e se caracteriza pela forma como o sujeito elabora ou define a sua situação dentro de um dado fenômeno sócio-cultural, no nosso caso, o processo saúde- doença ${ }^{(1-2)}$.

Diante do sofrimento de um dos seus membros, os familiares são chamados a agir e a refletir sobre a natureza do problema e as atitudes que devem assumir. As narrativas dos familiares de pacientes são repletas de referências, a noites mal dormidas, atendendo as solicitações do paciente ou a preocupações com seu paradeiro; a repetidas e quase sempre mal sucedidas jornadas a centros de tratamento; a brigas dentro e fora de casa; ao desespero por desconhecerem a causa da doença, se terá cura e quando a aflição terá fím.

A enfermidade, portanto, não é meramente um estado de sofrimento, mas também uma realidade social e

a família é o principal locus do cuidado dos doentes, no qual se delineiam boa parte das decisões e estratégias para se lidar com a situação(2).

Podemos afirmar, então, que o aparecimento de um transtorno mental consiste em uma situação problema (para a família e o sujeito doente) que põe em movimento um complexo processo social. Esse processo, ainda que se inicie pelo indivíduo em aflição, em alguns casos, ele se desencadeia pelos membros de sua rede familiar, que, percebendo algumas mudanças no seu modo de interação social, definem tais perturbações como resultado de problema mental e (re) orientam suas ações relativamente àquele indivíduo ${ }^{(3)}$.

Para o doente, para seus familiares e pessoas que estejam mais próximas de seu convívio, a experiência do adoecimento implica em desorganização. A rotina é modificada e todos os comportamentos do enfermo são observados como resultado da doença. Em alguns momentos, os familiares do doente sentem-se incapazes de relacionarem-se com ele. Atribuindo essa atitude ao fato de desconhecerem a doença (o que faz com que atividades rotineiras tornem-se impraticáveis) e mostrando-se ineficazes para atender a qualquer situação cotidiana.

Essa dificuldade e desorganização afetam diretamente a imagem que as pessoas fazem do doente mental, distorcendo-a e fazendo com que essa possa ser atrelada a do louco furioso, sujo, coitado, incapaz, despertando assim sentimentos que podem afetar a interação com o enfermo e, conseqüentemente, seu itinerário terapêutico, pois o doente furioso deve ser internado em locais fechados, o que é tranqüilo pode ser levado aos serviços abertos, o incapaz deve ser tratado como tal e assim por diante ${ }^{(\mathrm{a})}$.

Diante desse cenário, o doente e seus familiares são chamados a tomar atitudes e discursos normalizadores que possam modificar essa imagem, transformando-a em algo positivo. Quando os mesmos têm êxito nesse intuito, a conduta dos outros frente ao doente é reorientada, reconstruída, e a experiência perturbadora é afastada, tornando, assim, o convívio cotidiano mais ameno ${ }^{(4)}$. A experiência da enfermidade expressa-se por uma tentativa da família e do doente em alcançar um padrão de normalidade aceito culturalmente e ,portanto, legitimado. Tentando conhecer o que está fora do espaço social e cultural criado para os que vivem com (e apesar do) transtorno mental, buscamos, por meio deste estudo, compreender e analisar o itinerário do usuário de saúde mental, por meio da história oral de vida de um paciente psiquiátrico, para entender como a enfermidade se incorpora ao seu cotidiano.

Acreditamos que conhecer o itinerário terapêutico das pessoas com transtorno mental talvez seja uma forma de elucidar os modos pelos quais esses indivíduos se reorientam em um mundo de relações, atividades e planos individuais e coletivos que são, por vezes, profundamente alterados pela doença.

\section{METODOLOGIA}

A antropologia, ao longo do tempo, registrou interpretações culturais sobre diferentes tipos de aflição, entre elas, a doença, de-
Ouvindo outras vozes: relato de familiares sobre o convívio com o paciente psiquiátrico

\footnotetext{
(a)Sobre o conceito de imagem, ver Sartre JP. A imaginação. São Paulo: Difusão Européia do Livro; 1967.
} 
Amanda Márcia S. Reinaldo Toyoko Saeki

\footnotetext{
(b) Segundo a mitologia grega Hades é o deus do invisível, Tique a deusa do acaso e Adonis um ser ligado as plantações (Adonis é agrônomo aposentado)
}

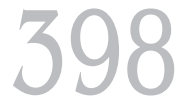

Rev Esc Enferm USP 2004; 38(4): 396-405. monstrando interesse no significado e nas formas de seu enfrentamento nas diferentes culturas.

Para a antropologia, as expectativas, juízos e reações das pessoas baseiam-se em comportamentos previamente reconhecidos como problemáticos em contextos similares, logo, baseados em signos (comportamentos, ações, descrições), interpretados e contextualizados. Esses signos podem estar relacionados às causas das doenças e outras questões, tais como: o que é a doença? como isto aconteceu? quem ou o quê a produz? por que isso ocorreu nesse momento em particular? por que isso aconteceu comigo?

Os relatos das experiências de doença e suas representações são partes inseparáveis das estratégias narrativas, amplamente utilizadas nos estudos antropológicos, e pelas quais são descritos os comportamentos das pessoas abaladas pelo sofrimento imposto pela enfermidade. As experiências e eventos expressos pela fala, contados e recriados pela história do vivido dão forma ao sofrimento individual e apontam para uma determinada compreensão ou resolução desse sofrimento.

O método utilizado neste estudo foi a história oral de vida. Trata-se de uma metodologia qualitativa de pesquisa, adequada ao conhecimento do tempo presente; que permite conhecer a realidade passada e atual, pela experiência e pela voz daqueles que a viveram. A escolha desse método deu-se por entendermos que reconstituir uma história de adoecimento envolve a narração de acontecimentos, ações ou particularidades referentes ao tema. A outra questão determinante para sua escolha é que acreditamos no potencial que ele tem para nos esclarecer sobre a vida das pessoas com transtorno psiquiátrico e como convivem com as limitações que a doença impõe diariamente. Pensamos que essa compreensão permite aproximarmo-nos do horizonte de quem vivencia a doença, colaborando para a construção do conhecimento a esse respeito ${ }^{(5)}$.

A análise foi realizada a partir de alguns conceitos do interacionismo interpretativo, que é uma perspectiva teórica e metodológica que, pela captura das vozes, emoções e ações das pessoas, tenta tornar a experiência vivida diretamente acessível ao leitor. A epifania é o foco da pesquisa interpretativa e reportase a (s) experiência (s) que radicalmente alte- ra e molda o significado que a pessoa dá a si mesma e a seus projetos de vida ${ }^{(6-7)}$.

Estaremos apresentando os relatos dos pais do sujeito deste estudo, que tiveram seus nomes trocados para preservar assim suas identidades: o colaborador primordial é chamado de Hades, seu pai é Adonis e sua mãe, Tique, fazendo menção aos deuses da mito$\operatorname{logia}$ grega $^{(\mathrm{b})}$. Foram realizadas cinco entrevistas com Hades, três com Tique e duas com Adonis.

A história de Hades e as considerações de seus pais sobre o convívio com ele são apresentadas em forma de crônica $^{(8)}$. Acrescentamos à mesma nossas impressões e anotações do diário de campo, tendo sido garantido aos entrevistados o sigilo quanto à identidade, visando resguardar a sua privacidade.

Para a realização deste trabalho, estamos considerando os aspectos éticos da resolução CNS $196 / 96^{(9)}$. O projeto de pesquisa foi analisado e aprovado pelo Comitê de Ética em Pesquisa da instituição onde o mesmo foi realizado e as entrevistas foram feitas na casa de Hades, em julho de 2002. O tempo médio das entrevistas foi de duas horas para cada encontro.

\section{Contando a história de Hades}

Hades sempre foi considerado uma criança "normal" ou quase isso, os pais dizem que ele era estranho, era "arteiro", gostava de brincar com os irmãos, amigos, era para eles como todas as crianças devem ser.

Ele antes de ir para a escola era alegre, [...] era normal, ele era muito alegre, depois que foi para escola, ficou mais fechado. (ADONIS)

Quando chegou a hora de ir para a escola, tudo era diferente, ambiente novo, novos amigos, "responsabilidades", "sair de casa" e havia uma professora que, segundo Adonis, não gostava dos meninos. Se tivessem atentado para isso antes, teriam transferido Hades de escola e tudo seguiria "o curso normal da vida", mas não, ele prosseguiu ali e então ele mudou, foi se fechando em "copas" como diz Tique, tudo começou ali, concorda Adonis, ele era diferente dos outros, naquela época descobriram que ele tinha descolamento de retina e isso também o tornava diferente. 
(...) esse problema dele começou... no pré (escolar), no pré mesmo quando ia começar o pré, aí que ele começou já naquela época dava pra ver que tinha algo errado, (...) as irmãs dele que eram mais novas foram passando na frente e ele foi ficando... . (TIQUE)

(...) desde criança a gente já notava que ele era muito tímido, tinha medo da escola, tinha medo...de tudo que era fora de casa, da professora, se a gente tivesse acordado, tinha trocado ele de escola(...) quando ele foi para a escola ele era pequeno, essa vista que tem problema ficava muito feia, hoje a gente nem nota né, mas na época era feio, (...) ele ia pra escola com medo. (ADONIS)

Quando adolescente, já era sabido por todos da família, que ele era diferente, Hades tinha um futuro anunciado de diferença e exclusão da vida, dos ambientes, das pessoas, enfim, de tudo. Cada vez mais tímido, sua mãe diz que ele puxou a ela, pessoa extremamente reservada e tímida. Não era só isso. Havia algo mais, era uma indecisão do que fazer, para onde ir, estudar, trabalhar, tudo era difícil demais, os irmãos foram saindo de casa, os amigos indo embora, mas ele não, foi ficando cada vez mais isolado, mais diferente, foi ficando para trás. Para Tique ele teve as mesmas oportunidades que seus irmãos tiveram de seguir o curso normal da vida, mas não pôde, para alguns, não quis.

(...) as irmãs dele que eram mais novas foram no vestibular, ele não passou na primeira vez, mais na segunda ele já passou, só que aí ele foi a contragosto e ele chegou a fazer um mês e meio, mas ou menos isso, (...) mas ele não freqüentou, ele desistiu, voltou pra casa, (...) e aí ele começou a ficar mais retraído mesmo (...) e foi aí que começou. (TIQUE)

Hades tinha muitos planos, queria ser geólogo. Tique nos conta que ele era muito inteligente, era um autodidata,

a psicóloga fez vários testes com ele e disse pra gente que não era nada na inteligência porque ele era muito inteligente $e$ que devia ser outra coisa, que ele era normal, não é que ele não entenda as coisas, não sei se é algum problema na vista, não sei, agora, inteligente ele é.

Não pôde estudar o que queria, pois o curso pretendido era geologia, mas a facul- dade ficava em outro Estado, não conseguiu, era muito difícil e sofrido pensar em sair de casa, passou na faculdade de química, difícil, boa e pública é o que dizem com orgulho os seus pais. Ele estava confuso, quando chegava para assistir as aulas não conseguia se concentrar, tudo era muito estranho assim como na escola primária, não queria estar ali, nem em local algum. Fico imaginando-o (como ele mesmo se descreveu) sentado embaixo das árvores do Campus, chorando, sujo por que já não se cuidava mais e sem explicação para aquilo que estava acontecendo. Tudo isso se agravou após o que ele chama de crise nervosa, tudo ficou estranho naquele período, ele foi se fechando, não conseguia mais pensar em nada, fazer nada, acabaram todos os planos.

Ele teve uma crise nervosa quando não
quis freqüentar a faculdade e ele ficou
esquisito, não queria mais tomar banho
nem cortar cabelo... (TIQUE)

Para Hades, tudo em sua volta era só preocupação. As dívidas do pai que, movido pelas crises de mania, (o pai de Hades é portador de Transtorno Afetivo Bipolar), gastava tudo o que a família possuía. Tique acredita que isso piorou o quadro de Hades porque ele foi o único filho que sentiu as dificuldades financeiras da família; todos os outros já moravam fora de casa, mas ele foi ficando, sendo

\section{enrolado pela doença. E depois também a vida pra nós foi ficando muito difícil, nós passamos por uma derrocada financeira muito grande (...) meus outros filhos não sentiram muito porque estavam todos fora de casa. (TIQUE)}

Tique relembra que foi difícil ver um filho adoecer, já seu pai diz que não, porque pior é ter um filho paraplégico, ladrão, drogado..., para ele a doença mental não foi o pior, já era esperado.

Foi difícil ver um filho que era tão solto, ficar (...) tão fechado. Daí ele se fechou em copas (...) sempre foi um touro, forte, pesado, gordinho (...) esse bloqueio que fez com que ele não fosse adiante (...) É um carma difícil, é um problemão. Nós ficamos perdidos com ele (...) agora quanto ao tratamento ele não dá trabalho, toma o remédio sozinho, nunca precisei mandar, ele é muito responsável nessa parte. (TIQUE)
Ouvindo outras vozes: relato de familiares sobre o convívio com o paciente psiquiátrico 
Amanda Márcia S. Reinaldo Toyoko Saeki
(...) Agora eu penso que tem coisa pior né, tem gente mongolóide por aí, paralítico que precisa dos outros pra fazer tudo, problema mental é o de menos, ele não é louco, não faz essas coisas que os outros fazem, agressivo, estranho demais, não (...) eu cheguei a conclusão que não tem cura, mas eu espero por um milagre disso e da vista dele... (ADONIS)

Os irmãos foram embora, mas exigiram por muito tempo do pai que levasse Hades para o médico, mas Adonis detesta os médicos (essa raiva é fruto de uma internação "forçada" que ele sofreu no passado). Adonis afirma que os médicos são homens de pouca fé, não acreditam em milagres, portanto, não são confiáveis. Então, levou para uma psicóloga e depois outra. Hades diz que naquela época ficou bem, não conhecia a doença, não sabia que era doente, mas conseguia controlar o que o assustava tanto.

(...) Adonis botou ele numa psicóloga, aliás duas e nenhuma deu jeito e aí foi piorando, piorando até os meus filhos falarem - ele tem que ir pro psiquiatra, que psicólogo não adianta nada (...) ele ficou uns 7 anos em tratamento com psicólogas... (TIQUE)

A derrocada financeira continuou e o tratamento não pôde ser retomado. Foi o próprio Hades quem decidiu, pois via que não dava mais para continuar, todo final de ano as dívidas acumulavam-se e os irmãos tinham que se reunir para tentar saldar os débitos que Adonis fazia.

Um ano passou e tudo piorou, novamente os irmãos entraram em cena, afinal, ele não podia continuar assim, algo tinha que ser feito e, sob protestos, Adonis levou Hades para uma consulta com um psiquiatra, que foi logo dizendo:

é muito grave, por que ele não está tomando remédio ainda? Eu só trato se ele for para o hospital-dia, ele tem esquizofrenia.

Eu levei o Hades pela primeira vez no psiquiatra e ele disse que a doença do Hades era muito grave, não falou o que era, só disse que era muito grave, e a gente já notava que tinha algo errado, ele era muito tímido. (ADONIS)

Agora todas as dificuldades tinham uma explicação, o medo de sair de casa, de se relacionar com os outros, o fato de nunca mais conseguir pegar um livro para ler, o choro, as preocupações, os pensamentos ruins, tudo se materializava em um nome, um diagnóstico. Naquele mesmo ano, Hades foi encaminhado para o hospital-dia de um hospital público do município de São Paulo.

(...) o psiquiatra disse que era grave, eu fiquei chocado (...) Essa doença, nem sei se o médico sabe mesmo o que é que ele tem, nem sei, mas uma vez disseram que é esquizofrenia... (ADONIS)

Quando chegou ao hospital-dia, tudo era muito estranho. Ele tinha medo da loucura e dos loucos do lugar e, por muito tempo, ficou assim até perceber, como se estivesse olhando em um espelho, que ali as pessoas chegavam de um jeito e com os dias mudavam o comportamento Ficavam calmas e diferentes, voltavam ao normal Daí ele percebeu o quanto estava doente e se lembrou de seu pai na mania e na depressão.

Já se passaram dez anos desde que Hades entrou naquele local pela primeira vez. Suas impressões a seu respeito foram com o tempo modificando-se, assim como o próprio Hades. Ele pôde acompanhar a entrada e a saída dos funcionários, períodos em que várias atividades eram oferecidas aos usuários e outros em que elas eram suspensas. Acompanhou a entrada de outros pacientes que, assim como ele, permanecem em acompanhamento no hospital.

Durante o uso da primeira medicação, ele apresentou alguns efeitos colaterais e ficou com medo das outras, trocou de medicamento e aprendeu que o medicamento não é suficiente para o controle da doença. Atualmente, desconfia que a medicação já não está adiantando muita coisa. Ele mudou e foi mudado pela doença, hoje, diz que a doença é só sofrimento, ela te enrola, está dentro e fora, e se não vigiar ela toma conta de você.

O fato de não lavar a cabeça e sua indisposição diária, muitas vezes, contribuiu para que a higiene corporal fosse deixada de lado, o excesso de peso, as roupas, os sapatos velhos e sujos, as saídas ao mercado à noite, entre tantas outras coisas que fazem parte do cotidiano de Hades e incomodam sua família. A vigilância em relação aos cuidados com o corpo é compartilhada com o hospital-dia, sendo algumas vezes transferida para a equipe daquele local. 
(...) ele me deixa tensa com isso (...) eu fico nervosa (...) ele come o dia todo (...) eu falo: tira a barriga da cabeça, pára de comer, aí ele diz que tá ansioso (...)eu falo: Hades assim você não agüenta (...) Eu falo todo dia: vai tirar essa roupa, vai trocar, vai cortar esse cabelo. Sabe quem dá jeito nele, a (enfermeira do hospitaldia), ela que conseguiu cortar o cabelo dele uma vez, só ela, ele escuta (...) tá faltando a (enfermeira do hospital-dia) pra ele, aquela ele ouve. Olha não é por conta da gente que ele anda assim não, porque a gente fala, (...) Hades você envergonha a gente, parece que aqui ninguém liga pra você! (...) é assim o dia todo: troca a roupa, corta o cabelo, toma banho, pára de comer... o dia inteiro (TIQUE)

A gente tem pena, ele não dá trabalho e às vezes só tem que chamar a atenção dele, às vezes ele teima em ficar aí usando roupa velha que já tá remendada, sem necessidade porque ele tem roupa nova... (ADONIS)

Para Tique o fato de ele não ter o que os irmãos têm família, dinheiro, carros, e ser pessimista, piora a situação, ou ainda, segundo Adonis, deve ser outra coisa, afinal esquizofrenia não lhe diz nada, é um signo dos profissionais de saúde, incompreensível, indecifrável, e que talvez nem os médicos saibam ao certo o que é.

(...) meus outros filhos conseguiram se formar, ter bens, todos eles têm carro. $E$ ele não, (...) e a empregada até fala: você tá assim porque quer, você não quis estudar, você parou, então, eles te deram a mesma chance que deram para os outros. Ele não pode falar que os culpados somos nós... mas sei lá será que é do problema? (TIQUE)

Ele teve esse azar de não conseguir aprender nada na faculdade, aí... Essa doença, nem sei se o médico sabe mesmo o que é que ele tem, nem sei, uma vez disseram que era esquizofrenia, então... também esse negócio de dizer que é esquizofrenia não adianta, isso é pro idioma de vocês, que vocês inventam, pra nós não quer dizer nada; pra gente o que é?... (ADONIS)

No meio de tudo isso alguns fatos aconteceram e foram se repetindo. Hades, cansado de ver o caos financeiro em que seu pai se afundara, resolveu tomar as rédeas do problema. Quando Adonis foi submetido a uma cirurgia, ele assumiu as contas da casa, passou a fazer as compras, controlar os gastos e anotar minuciosamente tudo o que era gasto.

Tudo isso ocupa grande parte de sua vida, pesquisa preços, faz as compras e anota tudo. Para ele foi uma vitória, pois passou a se sentir útil, contribuiu para que as dívidas acabassem, entretanto, para os seus pais isso é mais uma mania, uma distração, assim como o tratamento no HD. Hades define esse período como de grande crescimento pessoal.

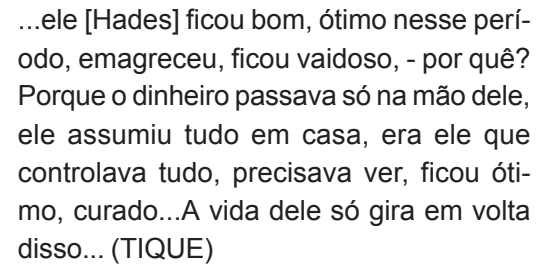

Eu acho que o Hades não melhorou nada, sabe, sei lá, por exemplo, lá no hospital [dia] ele ficou um tempo sem ir lá e parece que piorou um pouco, ele gosta de lá, distrai, fica melhor, mas bom não, as manias ele não deixa e se não deixa as manias é sinal que não tá bom, esse negócio dele ser pão duro, miserável é demais, é doentio, a gente fala mas ele não entende. (ADONIS)

"A doença que eu tive foi uma psicose", foi isso que Hades respondeu quando eu perguntei, mas a pergunta era: que doença você tem? No presente. Hades não acreditou no que ouviu do médico, achava que tudo o que estava acontecendo era resultado de suas preocupações com as dívidas que seu pai fazia quando estava em crise, com o fato de Adonis rejeitar o tratamento e sentir-se curado por um milagre de sua religião, diferente dele que hoje conhece a sua doença, sabe controlá-la, consegue diferenciar o que é seu e o que é dela.

A doença atrapalha, não deixa Hades fazer tudo o que tem que fazer, pois às vezes ele, por desânimo, acaba atrasando-se em seus afazeres do dia a dia. Ela faz com que ele esqueça as coisas, dá sono e contra isso só há duas coisas a fazer: a primeira, é tomar o remédio

- freio da doença, a segunda, é vigiar,
não deixar que ela tome conta de você.
(HADES)

Quando olha para trás, Hades vê que parou, está estacionado, sua vida não sai dessa rotina. Faz compras, consulta preços, anota
Ouvindo outras vozes: relato de familiares sobre o convívio com o paciente psiquiátrico 
Amanda Márcia S. Reinaldo Toyoko Saeki tudo, controla e vigia a doença, come, vai ao HD e dorme. Ele já mudou muito desde que entrou no hospital-dia, há dez anos. Hoje, com 39 anos, continua, como ele mesmo diz, no mesmo lugar, pois acabou seu grande crescimento, não consegue mudar sua rotina que o cansa e o irrita profundamente. Não tem amigos e as pessoas com quem se relaciona são as mesmas de 10 anos atrás, os usuários e técnicos do HD.

Hades vive o dia-a-dia, não faz planos e nem pensa no futuro. Acredita que, se perder tempo com isso, não conseguirá dar conta das tarefas do cotidiano. Pensando no futuro tanto ele como seus pais afirmam que tudo irá se arranjar, ele ficará recebendo a aposentadoria do seu pai, e existe a certeza de que os irmãos o ajudarão.

No ano de 2001, aconteceu um fato que fez com que ele tivesse uma recaída, ficasse mais desanimado e sonolento. $\mathrm{O}$ médico responsável pelo seu tratamento no hospital-dia foi embora. Hades ficou sabendo disso poucas semanas antes, e não sabia ao certo quando o terapeuta retornaria. A medicação foi acabando e sem receita ele diminuiu a dose para não ficar sem nada, ficou mais acelerado, os pensamentos ruins retornaram, tudo foi ficando difícil, então, ele foi encaminhado para o grupo de reintegração social do HD, para não ficar sem acompanhamento.

O grupo ajuda-o, mas Hades continua descuidando da higiene e engordando. Em casa, não fala sobre o que está acontecendo,

ele não fala nada do que faz no hospital e a gente também não pergunta. (TIQUE)

... eu acho que ele é mudo aqui e lá (Hospital Dia) porque ele não fala nada... (ADONIS)

Adonis concorda que tudo que seja relativo à doença deve ser falado no hospital.

...eu acho que aquele tratamento até ajuda, o Dr Cicrano era uma boa pessoa, mas foi embora, em médico eu não confio, confio nas pessoas e ele era uma boa pessoa. (ADONIS)

Também depois que o Cicrano foi embora, foi pior ainda, ele sentiu muita falta, ele sente ainda, porque o Cicrano dava apoio, ele ia lá e era melhor (...) e parece que ele não passou o caso do Hades pra ninguém, então... (TIQUE)
Há um pacto nessa família em que nada é falado, tendo-se a nítida impressão de que, assim como Tique e Adonis não querem chegar perto da doença do filho, este por sua vez prefere que eles se mantenham afastados. Justificativas para o não envolvimento também são dadas, contratos velados são feitos diariamente.

Olha, assim, aqui a gente não fala nada de doença mental, a gente não fala nada, nunca nós falamos, ele sabe que ele tem, mas a gente não fala, mas isso é lá no hospital, porque aqui não, ele podia ser debilóide, essas coisas mas isso ele não é, mas quando ele foi para o psiquiatra, ele disse que só tratava dele depois que ele fosse para o hospital-dia, mas não falou nada de doença não. (TIQUE)

Ele não comenta nada sobre isso e eu não gosto de comentar também, eu acho que ele acostumou, a gente discute algumas vezes e eu acho que até faz errado, porque a gente briga com esse negócio de andar com roupa velha, de economizar, mas vai saber se tá certo ou não brigar com ele. Mas a gente não chama ele de louco, nem doido, bobo, nada porque não vai resolver nada mesmo, todo mundo gosta dele (...) ele não é bobo e nem burro... (ADONIS)

O futuro ou a saída talvez fosse um trabalho para Hades. Seu pai pensa nisso, mas no momento não pode ajudá-lo. Também acha muito difícil ter que encarar uma rotina de trabalho, entretanto, queixa-se constantemente da rotina em que vive.

Hoje, o que mais o incomoda é a rotina, a falta de perspectiva de mudança, talvez a falta de coragem para mudar. Sente-se lesado pela doença e tudo o que ela tirou dele, todas as oportunidades de seguir o curso natural da vida, que, segundo ele, era estudar, trabalhar e formar uma família, assim como os irmãos. Adonis diz que tem pena de Hades, Tique é uma pessoa triste, que avalia ter perdido tudo com a doença dos dois, e que hoje faz uso de ansiolítico para manter-se calma e dormir.

Eu tô acostumada assim, o que eu já passei só Deus sabe... e ainda não acabou, porque são dois opostos, é assim, agora, eu não sei qual o motivo disso daí, não posso dizer a você porque eles são assim, não sei que... carga é essa. (TIQUE) 
E quanto a Hades, ele continua sendo "enrolado" pela doença. Ao vê-lo, tenho a sensação de estar vendo alguém que está tentando montar um quebra-cabeça, mas no meio do caminho já não encontra mais as peças, elas não se encaixam mais, então, ele senta e espera, vai vivendo o dia-a-dia sem pensar no futuro, escravo da rotina que ele mesmo criou.

\section{CONSIDERAÇÕES FINAIS}

O campo das investigações antropológicas sobre a doença mental mostra-nos que não podemos abordá-la sem considerar seus aspectos históricos e culturais, ou seja, não há como dissociá-los quando nos reportamos à experiência que as pessoas têm sobre a doença ${ }^{(5)}$. Entendemos que o processo saúde/doença encontra-se imerso em contextos sociais e culturais, envolvendo, portanto, significação, interpretação e ações socialmente organizadas para promover a saúde e responder à doença, e que o comportamento da pessoa em sofrimento psíquico está relacionado à forma como os sintomas da doença são dotados de significado e socialmente rotulados como negativos, aceitáveis ou não.

O sujeito do nosso estudo, durante o processo de adoecimento, foi isolando-se das pessoas à sua volta, quer fossem amigos e/ ou familiares e, conseqüentemente, hoje ele conta com uma rede social de apoio restrita. Percebemos que, após a aquisição do rótulo de doente mental, atribuído pelo diagnóstico, inicia-se um processo socialmente organizado de transformação do regime de vida do sujeito, que passa a exercer e assumir o papel de enfermo. Iniciado o papel de louco e consolidada essa imagem,observamos que a rede de subjetividade que o envolve não foi considerada no tratamento.

Isto implica dizer que estamos inferindo que não foram elaborados projetos para essa pessoa, ela não foi provocada a reordenar sua vida de forma mais criativa após o adoecimento, apesar de observarmos que Hades, por algum tempo, elaborou, e colocou alguns projetos que o aproximassem da imagem que ele tinha de normalidade. Não foram oferecidos a ele, por parte do serviço de saúde e da família, estímulos, investimentos ou sustentação para que essa iniciativa de elaboração de projetos não caísse na rotina da qual não vislumbra uma saída.
Alguns modelos explicativos são usados pela mãe de Hades para justificar o que aconteceu com ele. Entre esses modelos, a questão da personalidade, um traço pessoal como a timidez herdada e o pessimismo; questões corporais, como a queda do cabelo, o descolamento da retina. Entretanto, em momento algum ele fez referência à doença do pai como possível fator de risco. Quando cessam os argumentos para mostrar que a doença é incompreensível, tanto Adonis quanto Tique devolvem a questão e dizem não entender, em um diálogo de surdos. Dessa forma, a causa principal da doença é secundária, o que é observado é o comportamento do doente, a anormalidade da pessoa, ou seja, a causa é inerente ao sujeito, está dentro dele, pode ser tomada como um traço pessoal verificado quando se diz: ele sempre foi assim.

Assumir as finanças da casa leva Hades a reorganizar as contas da família. A doença que até então se conformava como fraqueza, incapacidade e como algo privado, pois só ocupa o espaço da casa e do hospital-dia, por uma iniciativa do próprio Hades passa a ser pública, iniciando-se um processo de ocupação de outros espaços, não só físicos, mas também no contexto familiar, no qual Hades impõe suas vontades e desejos de gerenciar os gastos da casa que lhe trazem tanto desconforto e preocupação.

Hades, por ter sido retirado do espaço público pela doença, como relata em sua história, retoma este espaço por meio do trabalho, começa a sair de casa para pagar as contas, fazer as compras e tentar "resolver a situação". A nosso ver, começa a fazer parte do tipo padrão de seu grupo social, ou seja, um homem que trabalha, produz e vive no espaço público. Entretanto, seu projeto de normalidade, ou seja, o trabalho, não é visto com credibilidade por seus pais, apesar de ser reconhecido como válido. Para nós, essa questão fica clara quando Adonis define as atividades de Hades como sendo de distração e ocupação, Tique faz uma leitura diferente, pois acredita que Hades ficou muito bem enquanto exercia esse papel, mesmo que não o entenda como uma tentativa de inserção laborativa.

Hades buscou por muito tempo concretizar no seu dia-a-dia seu projeto de normalidade, concebido como a possibilidade de "acertar as contas da casa", sendo vitorioso em um primeiro momento. Entretanto, apesar
Ouvindo outras vozes: relato de familiares sobre o convívio com o paciente psiquiátrico 
Amanda Márcia S. Reinaldo Toyoko Saeki dos investimentos e esforços contínuos, com o tempo ele vê a rotina apoderar-se do seu cotidiano. Não estamos aqui desmerecendo os projetos e ações de Hades, pelo contrário, eles fizeram com que ocorresse mudanças na maneira pela qual ele se percebia, fazendo com que o mesmo deixasse de ser espectador dos problemas financeiros da família e assumisse a posição de protagonista, conquistando assim a capacidade de auto-determinação e deixando de lado o rótulo de incapaz, geralmente atribuído ao doente mental. Naquele período Hades obteve o êxito da cura em si mesmo.

Isto implica dizer que estamos inferindo que não foram elaborados projetos para essa pessoa, que não foi provocada a reordenar sua vida de forma mais criativa após o adoecimento. Não foram oferecidos a Hades por parte do serviço de saúde e da família, estímulos, investimentos ou sustentação para que essa iniciativa de elaboração de projetos não caísse na rotina. $\mathrm{O}$ serviço, materializado nas pessoas que o acompanharam durante todo esse período, perdeu o mote da história de Hades. Para nós, perdeu a possibilidade de ajudá-lo, de intervir.

Hades formulou projetos e colocou-os em prática, havendo uma melhora significativa em todos os sentidos: ele ficou determinado, o autocuidado melhorou. Entretanto, quando Adonis se recupera e começa a sair de casa surge o conflito, Hades não tem mais todo o poder de decisão do que comprar, do que pagar e isso faz com que ele estacione; limitações foram impostas a suas decisões e ele não soube lidar com elas. A realização de suas ações requer um embate com Adonis, que, em alguns momentos, discorda da postura de Hades em relação ao dinheiro e sendo aquele que mantém a casa, visto que Hades não tem renda, surgem novos conflitos, cabendo a Tique tentar amenizá-los.

A ajuda por parte do serviço poderia terse dado por meio de instrumentos terapêuticos que possibilitassem maior intervenção junto ao paciente e a sua família, como as visitas domiciliares ou a figura do acompanhante terapêutico. A ocupação de novos settings, principalmente a casa do paciente e a comunidade, poderia estimular Hades a ocupar e criar espaços diferentes daqueles com os quais ele estava habituado. Intervenções, enfim, que possibilitassem que o isolamento do qual ele atualmente se queixa pudesse ter sido evitado.
Compreendemos que os projetos de Hades estavam consonantes com o contexto que se lhe apresentava e quando este se modificou ele não estava pronto para reorganizar sua vida. Essa observação assume contornos mais nítidos, quando ele avalia que seu crescimento pessoal estacionou. O "cuidar de si e de suas coisas" permanece, ele continua seguindo o tratamento sem incomodar sua família, está cansado de vigiar a doença para que ela não tome conta dele e entende que "o remédio é um freio" necessário.

O itinerário terapêutico de Hades está em curso. Observamos que o desencadeamento dos fatos narrados o levaram-no ao isolamento. Sua história não se limita à descrição objetiva de características, sinais e sintomas externos e internos da doença. A história de sua vida e a vida com a doença são, antes de mais nada, uma interpretação de uma situação específica, de uma experiência particular que reflete a vida desse indivíduo e a imagem que ele constrói de si mesmo, o que nos leva a crer que o itinerário terapêutico de Hades pode dizer muito mais da pessoa que fala do que sobre a doença propriamente dita.

É necessário enriquecer as redes familiares e sociais desses pacientes em termos quantitativos (serviços extra-hospitalares de apoio, profissionais qualificados) e qualitativos (apoio, informação, pesquisas, entre outros), unindo esforços para que a história de Hades não seja considerada apenas uma biografia individual ou o itinerário terapêutico possível de um portador de transtorno mental sem maiores implicações no cuidar.

Os sonhos e as aspirações das pessoas com transtorno psiquiátrico podem ter que ser modificados para incluir a doença mental. Acreditamos que incluir seja o grande desafio da saúde mental, e possibilitar essa inclusão, a nosso ver, deve ser a meta dos profissionais que atuam nesse campo. 
(1) Rabelo MC, Alves PC, Souza IM. Experiência de doença e narrativa. Rio de Janeiro: Editora Fiocruz; 1999. (Coleção antropologia e saúde).

(2) Duarte LFD, Leal OF. Doença, sofrimento, perturbação, perspectivas etnográficas. Rio de Janeiro: Editora Fiocruz; 1998. (Coleção antropologia e saúde).

(3) Velho G. Individualismo e cultura.. Rio de Janeiro: Zahar; 1994. Projeto, emoção e orientação em sociedades complexas; p. 154-62.

(4) Da Matta R. Relativizando: uma introdução à antropologia social. Petropólis: Vozes; 1981.

(5) Debert GG. Problemas relativos à utilização da história de vida e história oral. In: Cardoso RCL. A aventura antropológica. Teoria e pesquisa. $2^{\mathrm{a}}$ ed. Rio de janeiro: Paz e Terra; 1998. p. 64-78.
(6) Denzin NK. Interpretative interationism. Newburry Park: Sage; 1989.

(7) Lieblich A, Tuval-Maschiach R. Narrative research: reading, analyses and interpretation. Thousand Oaks: Sage; 1998. (Series: Applied social research methods, 47).

(8) Coffey A, Atkinson P. Making sense of qualitative data: complementary research strategies. Thousand Oaks: Sage; 1996. Narratives and stories; Chap 3, p. 54-81.

(9) Ministério da Saúde. Conselho Nacional de Saúde. Resolução n. 196/96. Dispõe sobre normas de pesquisa envolvendo seres humanos. Brasília; 1996.
Ouvindo outras vozes: relato de familiares sobre o convívio com o paciente psiquiátrico 